\title{
Analysis of a Structural Equation Model of Mothers' Responsive or Restrictive Parenting and Covert Narcissism and School Adjustment in School Children
}

\author{
Ha Young Min \\ Professor, Department of Child Studies, Daegu Catholic University, Gyeongbuk, Korea \\ 지각된 어머니의 반응/제한적 양육행동, 학령기 아동의 내현적 자기애와 \\ 학교 적응 간 구조모형 분석 \\ 민하영 \\ 대구가톨릭대학교 아동학과 교수
}

Objectives: The purpose of this study was to analyze a Structural Equation Model (SEM) of mothers' responsive or restrictive parenting and covert narcissism and school adjustment among school children.

Methods: The participants were 329 elementary school children in Daegu and Gyeongbuk Province. Self-reporting questionnaires were used to investigate the mothers' responsive or restrictive parenting perceived by children and covert narcissism and school adjustment among school children. Results: The results were obtained using SEM and are as follows. First, mothers' responsive parenting positively influenced children's covert narcissism, and mothers' restrictive parenting negatively influenced children's covert narcissism. Second, children's covert narcissism had a positive influence on school adjustment. Third, mothers' responsive and restrictive parenting perceived by children indirectly influenced school adjustment by children's covert narcissism.

Conclusion: For children's school adjustment, covert narcissism could be managed by more responsive and less restrictive parenting.

Keywords: responsive parenting, restrictive parenting, covert narcissism, school adjustment, schoolage children

\section{Introduction}

초등학생을 ‘학령기 아동’으로 지칭하는 것은 생애 처음 공식 적인 학교 교육이 시작되기 때문이다. 학령기 아동의 학교 적 응은 청소년기 중고등학교 적응의 기반이 될 뿐 아니라 성인 기 사회 적응을 예측하는 주요 지표로 평가되고 있다. 이는 학 령기 아동의 학교 적응이 생애 발달 측면에서 중요한 의미를 갖고 있음을 의미하는 것이다. 따라서 학령기 아동의 학교 적

Corresponding Author: Ha Young Min, Professor, Department of Child Studies, Daegu Catholic University, Hayang-Ro 13-13, Hayang-Eup, Gyeongsan-Si, Gyeongbuk, Korea

E-mail: hymin@cu.ac.kr
응은 가정과 학교 모두의 주요 관심사라 할 수 있다. 학령기 아 동의 학교 적응 중 학업에 대한 문제나 또래 관계 문제는 학교 적응을 나타내는 중요 축이라 할 수 있다(Boo, 2009; H. Shin, Park, Park, \& Lyu, 2006). 초등학교 고학령의 경우 중학교 진학 등으로 인해 학업에 대한 요구와 압력이 저학년에 비해 구체 화(Son, Lee, \& Lee, 2015)될 뿐 아니라 또래 관계의 중요성이 본격적으로 강조(S. Yoo, Park, \& Doh, 2015)되기 때문이다.

전통적으로 학교 적응 연구에서는 학업 성취나 성적에 대

(C)The Korean Association of Child Studies

This is an Open Access article distributed under the terms of the Creative Commons Attribution Non-Commercial License (http:// creativecommons.org/licenses/by-nc/4.0) which permits unrestricted noncommercial use, distribution, and reproduction in any medium, provided the original work is properly cited. 
한 문제가 강조(Sturge-Apple, Davies, Winter, Cummings, \& Schermerhorn, 2008)되었다. 그러나 학업 뿐 아니라 사회적 관 계 안에서의 정서적 적응이 학교 적응에서 중요하게 평가되 어야 한다는 시각이 제안(Ladd, 2004; Ladd, Kochenderfer, \& Coleman, 1997)되면서 친구와의 관계 등을 학교 적응의 주 요 준거로 활용하는 연구들(Dupere, Archambault, Leventhal, Dion, \& Anderson, 2015; H. Shin et al., 2006)이 증가하고 있다. 이러한 움직임들을 고려해 볼 때, 학령기 아동이 지각하는 학 업과 관련된 스트레스 뿐 아니라 또래와 관련된 스트레스는 아동의 학교 적응을 반영하는 의미있는 지표라 할 수 있다. 환 경적 요구에 비해 개인 내적 자원이 부족하거나 자신의 욕구 가 환경적 요구에 비해 크다고 평가될 때 부정적 정서인 스트 레스가 발생된다는 것(Lazarus \& Folkman, 1984)을 생각해 보 면, 학업이나 친구 관련 스트레스는 학교 환경 요구에 대한 아 동 자신의 욕구나 수용 정도를 인지적으로 이미 판단하여 반 영하는 것이라 할 수 있다. 따라서 학업이나 친구 등 학교 관련 스트레스는 학령기 아동이 지각하는 학교 적응의 질을 반영하 고 있다고 볼 수 있다. 특히 “학교가 좋다.”는 등의 긍정적 정 서처럼 “학교에 가면 혼자라는 생각에 외롭다."거나 “학교에 가기 싫다.”는 등의 부정적 정서가 학교 적응을 나타내는 중요 요소로 다루어지고 있음(Dupere et al., 2015; Erath, Flanagan, \& Bierman, 2008; Ladd, 2004; Ladd et al., 1997; Sturge-Apple et al., 2008)을 고려해 보면 학업이나 친구 관련 스트레스는 부정적 정서 측면에서 학교 적응을 접근하는 예가 될 수 있다.

학교 적응은 학교 생활에 관한 것임에도 불구하고 가정 생 활에서 경험하는 부모와의 관계는 학교 적응을 설명하는 주 요 요인으로 지목되고 있다(Sturge-Apple et al., 2008; Wang \& Fletcher, 2016). 학업에 대한 부담이나 요구의 주요 주체자일 뿐 아니라 또래 관계 형성 시 중요한 역할을 하는 내적 실행 모델 의 주요 원천자가 바로 주 양육자인 부모이기 때문이다. 따라서 학령기 아동의 학교 적응을 반영하는 학업이나 또래 관련 스트 레스를 가정 내 부모와의 관계 측면에서 설명할 필요가 있다.

학령기 아동과 부모와의 관계 중 주 양육자인 어머니의 양 육행동은 학령기 아동의 적응을 예측하는 중요한 가정 내 변 인이다. 어머니의 양육행동은 자녀를 양육함에 있어 일반적으 로 나타내는 태도 및 행동으로(Becker, 1964), 애정적이며 민주 적인 양육행동으로 설명되는 반응적 양육행동은 긍정적 양육 행동의 예라 할 수 있다. 그리고 일방적이며 강요적인 양육행 동으로 설명되는 제한적 양육행동은 부정적 양육행동의 예로 설명되고 있다(Coolahan, McWayne, Fantuzzo, \& Grim, 2002). 이러한 어머니의 양육행동은 학교 적응과 유의한 관련성이 있
는 것으로 보고(Dupere et al., 2015; Ladd, 2004; Sturge-Apple et al., 2008)되고 있다.

어머니의 양육행동이 온정적이고 합리적이며 수용적이고 헌신적이며 자녀의 의견과 권리를 존중하는 등의 지지적이며 애정적이라 지각하는 아동의 경우, 학업 스트레스는 상대적으 로 낮은 것(Y. Yoo \& Park, 2010)으로 나타나고 있다. 뿐만 아니 라 이런 아동은 친절하고 사교적이며 자신의 감정을 쉽게 표 현하고 정서적으로 안정된 특성을 나타낼 뿐 아니라 또래 관 계에서 낮은 수준의 스트레스 및 외로움을 경험하는 것(Chen, Chang, He, \& Liu, 2005; Sturge-Apple et al., 2008)으로 보고되 고 있다. 이에 반해 어머니의 양육행동이 비난적이며 체벌적 이고 엄격하고 통제가 많으며 부모의 권위를 강조하거나 무 조건적인 복종을 요구하는 등의 제한적 양육행동이라 지각하 는 아동의 경우, 학업 관련 스트레스는 높고(Ahn, 2016; K. H. $\mathrm{Kim}, 2014)$, 또래 관계에선 많은 어려움을 경험하고 있는 것 (Chang, Schwartz, Dodge, \& McBride-Chang, 2003)으로 나타났 다. 이러한 사실은 어머니의 양육행동이 학령기 아동의 학교 적응에 영향을 미치고 있음을 의미한다.

한편 아동의 내적 자아 특성은 어머니의 양육행동에 의해 발달한다고 하지만 독립적 존재로 성장해 가고 있는 초등학교 5,6 학년 아동의 내적 자아는 주 양육자인 어머니의 양육행동 처럼 학교 적응에 영향을 미치는 요인으로 고려될 수 있다.

학령기 아동의 내적 자아 중 내현적 자기애는 특히 아동의 학교 적응에 있어 주의해야할 자아 특성이다(Barry, Frick, \& Killian, 2003; Pauletti, Menon, Menon, Tobin, \& Perry, 2012). 내 현적 자기애란 거대자기 환상, 과시성, 자기 몰두, 자기 중요라 는 내적 특성으로 설명되는 내/외현적 자기애 중 타인의 평가 나 반응에 대해 민감하며 쉽게 상처받는 등의 특성을 지닌 자 기애를 말한다(Atlas \& Them, 2008; Wink, 1991). 외현적 자기 애와 달리 역기능과 부적응 측면에서 일관된 예후를 나타내는 내현적 자기애(Malkin, Barry, \& Zeigler-Hill, 2011; Rose, 2002) 는 손상되기 쉬운 자기 자신을 보호하기 위해 사회적으로 부 과된 완벽수준이 높고, 비판과 비난을 원천 봉쇄하기 위해 비 난의 단서가 없는지 타인의 의견에 민감하게 반응하며 단정적 이거나 확언하는 등의 말을 피함으로써 자기를 보호하는 성향 을 지닌다. 이러한 성향은 사회적으로 부과된 완벽수준이 높 기 때문에 부모의 학업에 대한 기대와 성적 성취에 보다 민감 할 수 있다. 사회적으로 부과된 완벽주의는 지나치게 높은 기 준을 자기 자신에게 부여하고 기준에 도달하고자 노력하게 만 든다. 그러나 이상적 기준과 현실적 수행 사이의 괴리를 경험 하는 과정에서 자기 비난 등의 심리적 어려움을 심화시킨다. 
뿐만 아니라 거절에 대한 민감성이 크기 때문에 대인관계에서 어려움을 느끼며(Hendin \& Cheek, 1997), 부정적인 평가를 미 리 예상하기 때문에 이러한 예상에 대해 늘 과민한 모습을 나 타낸다(Chung, 2001; Foster \& Trimm, 2008). 실질적으로 내현 적 자기애적 중학생은 학교 수업에서 어려움을 경험하며 이로 인해 우울감을 경험하는 것으로 나타났으며(B. R. Shin \& Lee, 2018), 시험 불안이 높은 것(Choi, 2005)으로 나타났다. 그리고 거절에 대한 높은 민감성과 또래의 비판과 비난 또는 평가에 과도하게 반응하는 특성 때문에 내현적 자기애가 높은 학령기 아동은 또래 관계에서 더 많은 심리적 어려움을 나타냈다(Lee \& Hong, 2016; Pauletti et al., 2012). 이는 학령기 아동의 내현 적 자기애적 성향이 학업이나 친구 관계와 관련된 학교 적응 에 유의한 영향을 미치는 내적 자아임을 의미하는 것이다.

그러나 여기서 고려할 점은 내현적 자기애가 부모로부터 지 속적인 이해와 공감을 받지 못하고 애정결핍적 양육을 받게 될 때 나타나기 쉽다는 시각(Kernberg, 1975; Kohut, 1977; Park \& Hong, 2014; Trumpeter, Watson, O'Leary, \& Weathington, 2010) 과 부모가 자녀를 완벽한 존재로 믿고 특별한 존재로 키울 때 나타나기 쉽다는 시각(Horton, Bleau, \& Drwecki, 2006; Watson, Hickman, Morris, Milliron, \& Whiting, 1995; Watson, Little, \& Biderman, 1992)이 제안되고 있다는 것이다. 이는 부모의 양육 행동이 내현적 자기애 발달에 영향을 미친다는 점이다. 이러한 사실은 학령기 아동의 학교 생활 스트레스와 관련된 학교 적응 을 설명하는 내현적 자기애가 부모의 양육행동에 의해 영향받 을 수 있음을 의미하는 것이다. 이는 부모의 양육태도가 내현적 자기애를 매개로 대학생의 우울(Kang \& Jin, 2018)이나 학령기 아동의 공격성(Chun, 2015)에 간접 영향을 미치듯, 학령기 아동 의 학교 적응에 영향을 미치는 부모의 양육행동도 내현적 자기 애를 통해 간접적으로도 영향 미칠 수 있음을 시사하는 것이다.

특히 부정적 양육행동이 내현적 자기애 발달에 미치는 영 향력(Kernberg, 1975; Kohut, 1977; Park \& Hong, 2014; Ramsey, Watson, Biderman, \& Reeves, 1996)을 고려해 볼 때, 일방적이 며 강압적이며 제한적인 양육행동이 내현적 자기애를 통해 학 교 적응에 미치는 직 간접 영향력은 애정적이고 지지적이며 반응적인 양육행동이 미치는 영향력과는 차이를 보일 가능성 이 있다. 이는 부모의 양육행동을 긍정적 양육행동과 부정적 양육행동으로 구분해 접근하는 것이 바람직함을 시사하는 것 이다. 이에 이 연구에서는 학령기 아동의 학교 적응에 어머니 의 양육행동(Dupere et al., 2015; Ladd, 2004; Sturge-Apple et al., 2008)과 내현적 자기애가 영향(Choi, 2005; Lee \& Hong, 2016; Pauletti et al., 2012)을 미친다는 점 그리고 어머니의 양육행
동이 내현적 자기애에 영향을 미친다는 점(Kernberg, 1975; Kohut, 1977; Park \& Hong, 2014; Trumpeter et al., 2010)을 고려 해, 학령기 아동이 지각한 부모의 양육행동을 반응적 양육행 동과 제한적 양육행동으로 구분한 후 내현적 자기애와 관련하 여 부모의 양육행동이 학교 적응에 어떤 영향을 미치는지 구 조방정식 모형을 토대로 살펴보고자 한다. 이를 위해 Figure 1 의 연구모델과 다음과 같은 연구문제를 설정하였다.

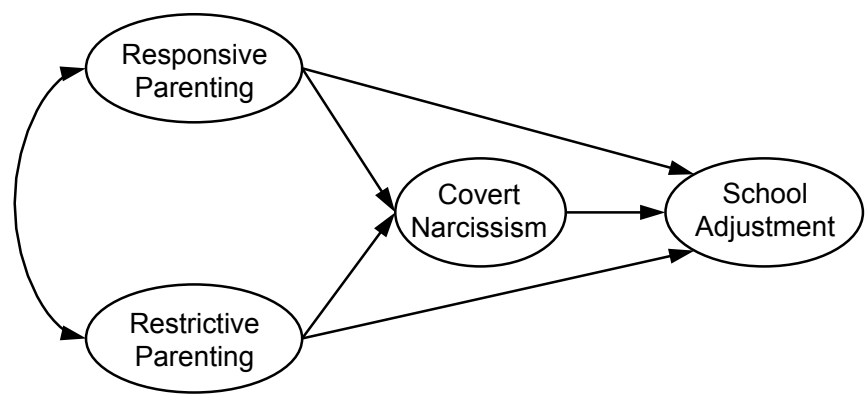

Figure 1. Model of the study.

\section{연구문제 1}

학령기 아동의 학교 적응에 대한 지각된 어머니의 반응/제한 적 양육행동과 아동의 내현적 자기애의 영향은 어떠한가?

1-1 학령기 아동의 학교 적응에 대한 지각된 어머니의 반 응/제한적 양육행동의 영향은 어떠한가?

1-2 학령기 아동의 학교 적응에 대한 아동의 내현적 자기 애의 영향은 어떠한가?

1-3 학령기 아동의 학교 적응에 미치는 아동의 내현적 자 기애를 통한 지각된 어머니의 반응/제한적 양육행동의 간 접 영향은 어떠한가?

이와 같은 연구문제의 결과는 학령기 아동의 학교 적응을 지원할 수 있는 방안을 가정과 학교가 함께 모색해 볼 수 있는 기초 정보나 자료로 활용될 수 있을 것이다.

\section{Methods}

\section{연구대상}

연구대상은 $\mathrm{K}$ 지역에 소재한 초등학교 5, 6학년에 재학 중인 
329 명(5학년 186명, 6학년 143명)으로 남아 160 명, 여아 169 명이었다. 학령기 아동의 학교 적응과 관련해서 초등학교 5, 6 학년 아동을 대상으로 한 것은 초등학교 고학년은 중학교 진 학에 대한 부담과 학업 스트레스가 가중되는 시기(Son et al., 2015)일 뿐 아니라 또래 관계에서 수용과 거부가 주관적 안녕 감에 영향을 미칠만큼 또래 관련 스트레스가 중요한 시기(S. Yoo et al., 2015)라는 점, 그리고 자아가 보다 안정적이고 명확 하게 나타나는 시기(Harter, 1982)라는 점과 질문지 조사에서 자신의 의견을 자신의 관점에 따라 능동적이며 자율적으로 참 여할 수 있다는 점을 고려한 것이다.

연구 대상 아동의 어머니 중 40 대 미만 어머니는 160 명, 40-45세 140명, 46세 이상은 29명으로 나타났다. 자료는 자기 보고식 질문지법을 이용하여 수집하였으며 이를 위해 사용된 연구의 척도는 다음과 같다.

\section{연구도구}

\section{지각된 어머니의 반응/제한적 양육행동}

학령기 아동이 지각한 어머니의 반응/제한적 양육행동을 측 정하기 위해서 Baumrind (1966)의 부모 양육양식 척도를 토대 로 Coolahan 등(2002)이 개발한 양육행동 척도를 사용하였다. 아동이 지각한 어머니의 반응적 양육행동(responsive parenting) 은 아동의 자율성을 존중하고 아동의 요구에 대해 온정적이고 수용적으로 반응하며, 합리적 설명에 기반해 아동을 설득하는 양육행동이다. "우리 어머니는 자식이 잘 해보려고 애쓸 때 자 랑스럽다고 말해주신다.”, “우리 어머니는 자식이 마음 상했 을 때, 그 마음을 이해한다는 표현을 해 주신다." 등의 16 문항 으로 이루어진 각 문항은 전혀 그렇지 않다(1점)에서부터 매 우 그렇다(4점)의 4점 Likert로 측정하였다.

제한적 양육행동(restrictive parenting)은 아동과의 상호작 용 시 비난적 태도를 보이며 체벌적 훈육을 사용하는 양육행 동이다. "우리 어머니는 자식이 애를 먹일 때 표나게 화를 내 신다.”, “우리 어머니는 자식이 말을 안들을 때 때리신다.” 등 의 12 문항으로 이루어졌다. 각 문항은 전혀 그렇지 않다(1점) 에서부터 매우 그렇다(4점)의 4점 Likert로 측정하였다. 척도 의 문항 간 내적 합치도에 의한 신뢰도 Cronbach's $\alpha$ 는 반응적 양육행동 .95, 제한적 양육행동 .85이며, 응답 점수가 높을수 록 어머니의 반응적 양육행동과 제한적 양육행동이 각각 높은 것을 의미한다. 한편 어머니의 반응적 양육행동과 제한적 양 육행동은 단일 척도로 구성된 문항이므로 구조방정식 모델 분
석을 위해 문항꾸러미 방법(item parceling method)을 이용하 여 반응적 양육행동1 (5문항), 반응적 양육행동2 (6문항), 반응 적 양육행동3 (5문항)과 제한적 양육행동1 (4문항), 제한적 양 육행동2 (4문항), 제한적 양육행동3 (4문항)의 하위척도를 구 성하였다. 문항꾸러미는 단일 척도에서 발생될 수 있는 추정 모수의 증가에 따른 추정오차의 문제를 해결하는 방법(Russel,

Kahn, Spoth, \& Altmaier, 1998)으로 단일 척도를 구성하는 문 항을 두 개 또는 그 이상의 문항으로 묶어 더한 점수나 평균점 수를 활용한다.

\section{학령기 아동의 내현적 자기애}

학령기 아동의 내현적 자기애를 측정하기 위해서 Hong, Gwak 과 $\operatorname{Han}$ (2010)이 개발한 아동용 내현적 자기애 척도를 사용하 였다. 내현적 자기애는 "다른 아이들이 나를 무시하면 똑같이 해준다.", "창피를 당하면 그것에 대해 계속 생각하고 괴로워 하는 편이다.", "나와 다르게 생각하는 사람을 보면 이해할 수 없다.” 등 착취와 공격성 5문항(내현적 자기애1), 과민성과 취 약성 6문항(내현적 자기애2), 자기중심성 7문항(내현적 자기 애3) 등 신뢰도를 떨어트리는 3 문항을 제외한 총 15 문항으로 이루어졌다. 각 문항은 전혀 그렇지 않다(1점)에서부터 매우 그렇다(4점)의 4점 Likert로 측정하였다. 척도의 문항 간 내적 합치도에 의한 신뢰도 Cronbach's $\alpha$ 는 .87이며, 응답 점수가 높 을수록 아동의 내현적 자기애 성향이 높은 것을 의미한다.

\section{학령기 아동의 학교 적응}

학령기 아동의 학교 적응은 Min과 Yoo (1998)가 개발한 학령 기 아동의 일상적 생활 스트레스 중학업 관련 스트레스와 또 래 관련 스트레스로 측정하였다. "성적이 떨어질까봐", "공부 를 잘하고 싶은데 공부방법을 몰라서" 등의 7 개 학업 관련 문 항(학교 스트레스1)과 "나를 좋아하는 친구가 없어서”, “친구 들이 내가 이야기 하는 것을 잘 들어주지 않아서" 등 또래 관 련 6문항(학교 스트레스2) 등 신뢰도를 떨어트리는 5문항을 제외한 총 13 개 문항으로 이루어졌다. 각 문항은 전혀 그렇지 않다(1점)에서부터 매우 그렇다(4점)의 4점 Likert로 측정하였 다. 척도의 문항 간 내적 합치도에 의한 신뢰도 Cronbach's $\alpha$ 는 .89이며, 응답 점수가 높을수록 학교 적응에서 스트레스를 많 이 받는 것을 의미한다. 
Table 1

Means, Standard Deviations, and Correlations Among Variables

\begin{tabular}{|c|c|c|c|c|c|c|c|c|c|c|c|c|}
\hline & & 1 & 2 & 3 & 4 & 5 & 6 & 7 & 8 & 9 & 10 & 11 \\
\hline 1 & Responsive parenting1 & - & & & & & & & & & & \\
\hline 2 & Responsive parenting2 & $.829^{* * *}$ & - & & & & & & & & & \\
\hline 4 & Restrictive parenting1 & $-.420^{* * *}$ & $-.315^{* * *}$ & $-.464^{* * *}$ & - & & & & & & & \\
\hline 5 & Restrictive parenting2 & $-.364^{* * *}$ & $-.274^{* * *}$ & $-.397^{* * *}$ & $.730^{* * *}$ & - & & & & & & \\
\hline 8 & Covert narcissism2 & $-.278^{* * *}$ & $-.200^{* * *}$ & $-.245^{* * *}$ & $.279^{* * *}$ & $.223^{* * *}$ & $.242^{* * *}$ & $.485^{* * *}$ & - & & & \\
\hline 9 & Covert narcissism3 & $-.330^{* * *}$ & $-.279^{* * *}$ & $-.331^{* * *}$ & $.307^{* * *}$ & $.220^{* * *}$ & $.276^{* * *}$ & $.553^{* * *}$ & $.497^{* * *}$ & - & & \\
\hline 10 & School stress 1 & $-.357^{* * *}$ & $-.301^{* * *}$ & $-.324^{* * *}$ & $.252^{* * *}$ & $.240^{* * *}$ & $.230^{* * *}$ & $.251^{* * *}$ & $.462^{* * *}$ & $.355^{* * *}$ & - & \\
\hline 11 & School stress2 & $-.328^{* * *}$ & $-.284^{* * *}$ & $-.304^{* * *}$ & $.239^{* * *}$ & $.232^{* * *}$ & $.223^{* * *}$ & $.293^{* * *}$ & $.432^{* * *}$ & $.310^{* * *}$ & $.513^{* * *}$ & - \\
\hline \multicolumn{2}{|c|}{ Kurtosis } & -.63 & -.45 & -.40 & -.32 & -.51 & .35 & .44 & -.04 & -.63 & -.57 & .03 \\
\hline
\end{tabular}

Note. $N=329$.

*** $p<.001$.

\section{연구절차}

대구경북지역 내 초등학교 5, 6학년 학령기 아동을 대상으로 질문지 조사를 실시하기 위해 조사를 허락받은 5 개 초등학교 에 아동학 전공의 석박사과정생들이 직접 방문하여 담임교사 에게 연구의 목적과 질문지 응답 요령을 설명하였다. 5, 6학년 아동들에 대한 질문지 배포와 수거는 담임교사에 의해 각각 이루어졌으며 수거된 질문지는 인편으로 연구자에게 전달되 었다. 구조방정식 모형 분석을 위해 결측 문항이 한 개라도 포 함된 자료 및 답변이 성실하게 이루어지지 않은 자료는 모두 제외하고 329명의 자료만을 분석에 사용하였다.

\section{자료분석}

수집된 자료는 연구모형 검증을 위해 SPSS 21.0 (IBM Co., Armonk, NY)을 이용하여 평균, 표준편차, Pearson의 상관계수 와 AMOS 10.0 (IBM Co., Armonk, NY)프로그램의 절대적합 지수인 $\chi^{2}, \mathrm{GFI}, \mathrm{RMSEA}$, 증분적합지수인 TLI, NFI, CFI값을 살펴보았다. 그리고 bootstrapping 절차를 이용하여 구조모형 에서 나타난 간접효과의 유의성을 살펴보았다.

\section{Results}

\section{측정 변인들의 일반적 경향}

학령기 아동의 학교 적응에 미치는 어머니의 반응적 양육행동 과 제한적 양육행동 그리고 학령기 아동 자신의 내현적 자기 애 간의 관계를 구조방정식 모형을 통해 살펴보기에 앞서 관 련 변인 상관관계 및 기술통계치인 평균(표준편차), 왜도, 첨 도를 분석하였다.

Table 1에 나타난 분석 결과를 살펴보면 관련 변인이 모두 4점 리커트로 측정된 사실을 고려해 볼 때, 어머니의 반응적 양육태도는 3점대 $(M=3.06 \sim 3.15)$ 로 높게, 제한적 양육행동 은 2점대 $(M=1.98 \sim 2.16)$ 로 낮게 나타났다. 내현적 자기애는 착취와 공격성, 과민성과 취약성, 자기중심성에서 2점대 $(M=$ $1.83 \sim 2.20)$ 에 나타났으며 학업 관련 스트레스 $(M=2.22)$ 는 또 래 관련 스트레스 $(M=1.58)$ 에 비해 높은 것으로 나타났다. 한 편 통계적 모델의 추정 방법을 결정하기 위해 다변인정규분 포성 검증을 실시하였다. 그 결과 왜도는 기준값인 3미만 값 이 나왔으며, 첨도는 기준값인 10 미만 값이 나왔으므로 정규 분포를 이룬다고 볼 수 있다(Kline, 2005). 이에 최대우도추정 (maximum likelihood estimation) 절차를 이용하여 모델의 적합 도와 모수치를 추정하였다. 


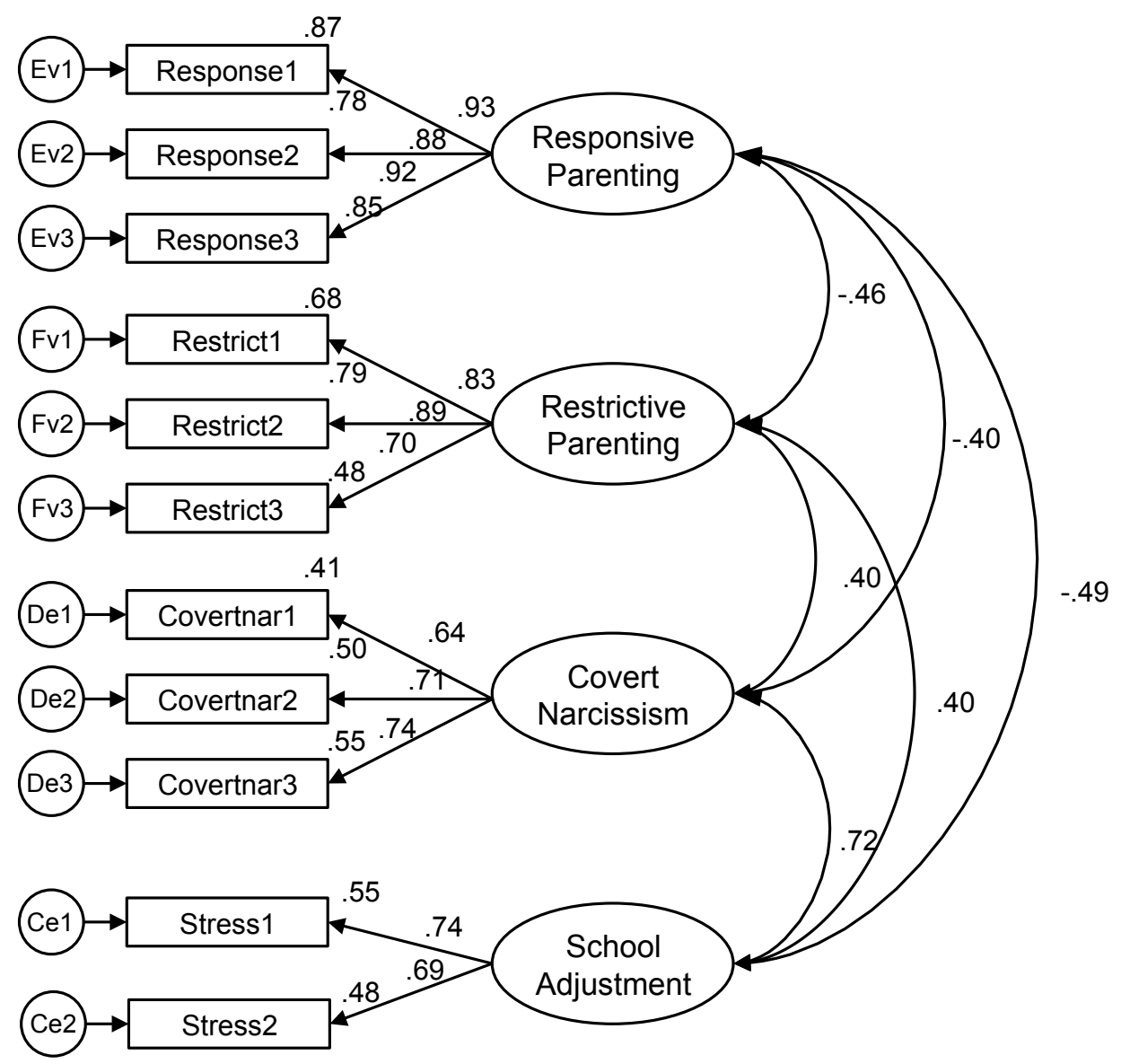

Figure 2. Confirmatory factor analysis model.

\section{지각된 어머니의 반응/제한적 양육행동, 학령기} 아동의 내현적 자기애와 학교 적응 간 관계 분석

학령기 아동의 학교 적응에 대한 지각된 어머니의 반응적, 제 한적 양육행동과 아동 자신의 내현적 자기애의 영향을 구조방 정식 모델(structural equation model)을 통해 검증하고자, 연구 모델 검증에 앞서 잠재변인들의 타당도를 검증하기 위해 확인 적 요인분석을 통한 측정모형의 검증을 실시하였다.

\section{측정모형의 검증}

확인적 요인분석(confirmatory factor analysis)을 통해 잠재변수 로 사용된 어머니의 반응/제한적 양육행동, 학령기 아동의 내 현적 자기애, 학교 적응의 측정변인들이 이론적 개념을 잘 반 영하고 있는지를 검토하기 위해 최대우도추정법을 적용하여 측정모델의 적합도(goodness of fit)와 모수치를 추정하였다. Figure 2에 나타난 바와 같이 측정모델의 적합도는 $\chi^{2}=89.93$ $(d f=38, p<.001), \mathrm{GFI}=.954, \mathrm{RMSEA}=.064, \mathrm{TLI}=.961, \mathrm{NFI}$ $=.954, \mathrm{CFI}=.973$ 으로 나타났다. 모형적합도 지수 기준값이 $\mathrm{GFI}>.90, \mathrm{RMSEA}<.08, \mathrm{TLI}>.90, \mathrm{NFI}>.90, \mathrm{CFI}>.90$ 인 점 을 고려해 볼 때 측정모델은 자료(data)에 적합하며, 이론적 개 념을 잘 반영하는 것으로 나타났다.

한편 Figure 2에 나타나듯 확인적 요인분석에서의 표준화 요인부하량은 기준치인 .50이상을 나타내고 있으며 잠재요 인에 대해 측정변수들이 설명할 수 있는 분산의 크기를 나타 내는 평균분산추출지수(average variance extracted)는 반응적 양육행동 .82 , 제한적 양육행동 .65 , 내현적 자기애 .51 , 학교 적응 .51 등 기준치 .50 이상으로 나타나 수렴(집중)타당성이 존재하고 있음을 확인하였다. 한편 평균분산추출지수의 모 든 값은 Figure 2에 나타난 잠재변인 간 상관계수의 제곱값보 다 크므로 판별타당성이 있음(Anderson \& Gerbing, 1988)이 확인되었다. 
Table 2

Summary of Model Fit Statistics

\begin{tabular}{lcccccccc}
\hline & \multicolumn{3}{c}{ Fit index } & \multicolumn{3}{c}{ Absolute fit index } & \multicolumn{3}{c}{ Incremental fit index } \\
\cline { 2 - 8 } Model & $\chi^{2}$ & $d f$ & $p$ & GFI & RMSEA & TLI & NFI & CFI \\
\cline { 3 - 9 } Hypothetical path model & 89.83 & 38 & .000 & .954 & .064 & .961 & .954 & .973 \\
Modified path model & 90.97 & 39 & .000 & .953 & .064 & .961 & .954 & .973 \\
\hline
\end{tabular}

Note. $\chi^{2}=$ chi-square; GFI = goodness-of-fit index; RMSEA = root mean squared error of approximation; TLI = Tucker-Lewis index; NFI $=$ normal fit index; CFI $=$ comparative fit index.

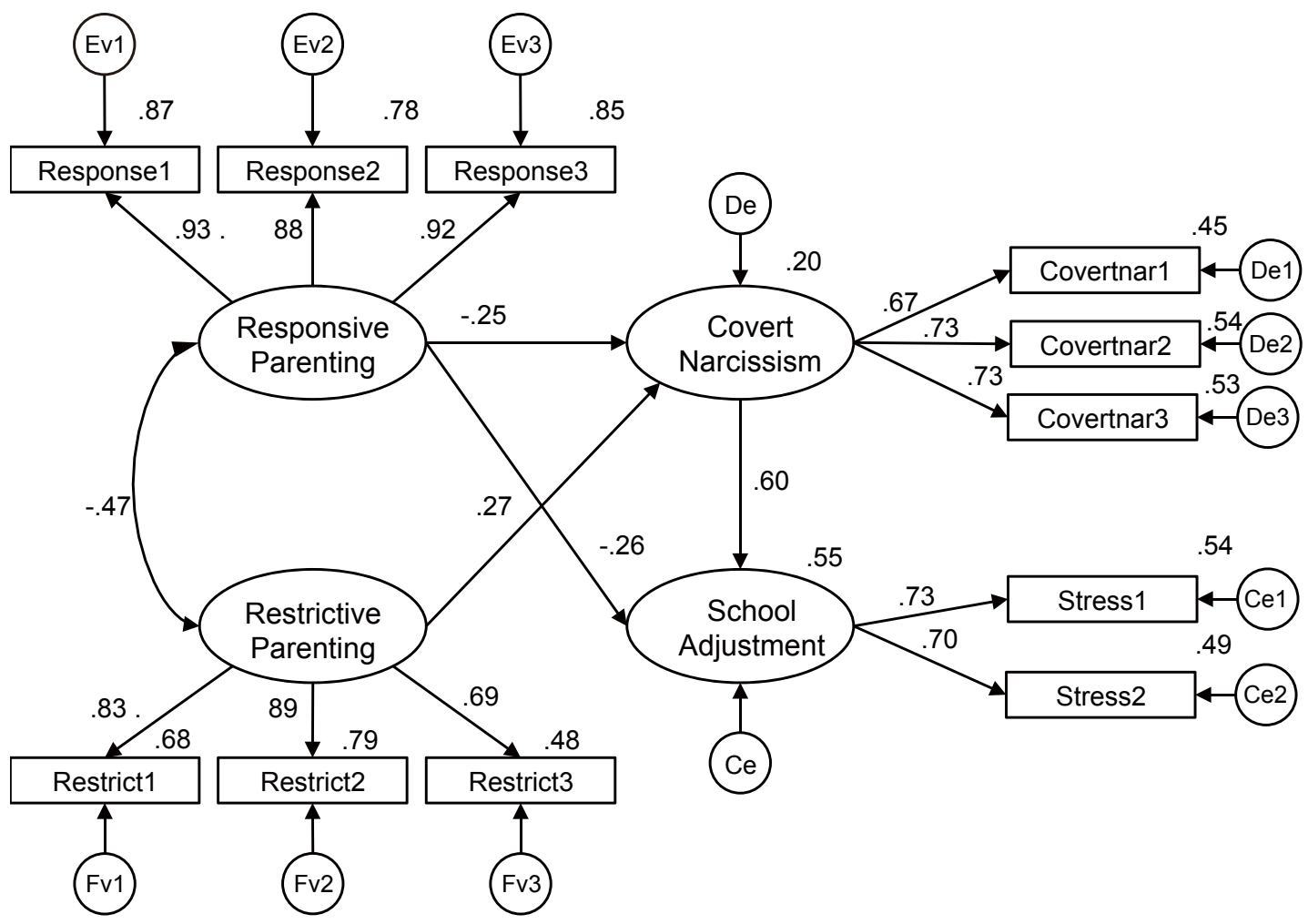

Figure 3. Final research model.

\section{연구모형 분석}

측정모델을 통해 개념이 자료를 통해 적합하게 측정되었음을 확인한 후 연구모델의 유의성을 검증하였다. 초기구조모델의 적합도 지수는 Table 2에 나타난 바와 같이 모델 적합도 기준 을 충족시켰으나 제한적 양육행동에서 학령기 아동의 학교 적 응 간 경로계수의 모추치 추정이 유의하지 않게 나타났다. 이 에 이 경로를 삭제시킨 수정된 구조모델을 설정하였다. 수정 된 구조모델은 Table 2에 나타나듯 적합도 지수가 모델 적합도 기준을 모두 충족시키는 것으로 나타났다. 이를 바탕으로 수 정된 구조모델의 모수치 추정 및 통계적 유의성을 확인한 결 과 모든 변인들 간의 관계는 Table 2에 나타난 바와 같이 통계
적으로 유의한 것으로 나타났다.

연구모형이 적합하다는 사실을 토대로, 연구문제 1-1, 1-2 와 관련된 경로 간 추정치를 표준화계수 $(\beta)$ 측면에서 살펴보 면 Figure 3과 같다. 그리고 비표준화계수 $(B)$ 까지 포함시켜 함 께 살펴보면 Table 3과 같다.

어머니의 제한적 양육행동과 달리 반응적 양육행동은 학 령기 아동의 학교 적응에 유의한 영향을 미치는 것 $(\beta=-.26$, $p<.001)$ 으로 나타났다. 그리고 어머니의 반응적 양육행동 $(\beta$ $=-.26, p<.001)$ 과 제한적 양육행동 $(\beta=.27, p<.001)$ 은 각각 학령기 내현적 자기애에 유의한 영향을 미치는 것으로 나타 났다.

마지막으로 연구문제 1-3의 간접영향을 알아보기 위해 
Table 3

Path Estimate of Final Research Model

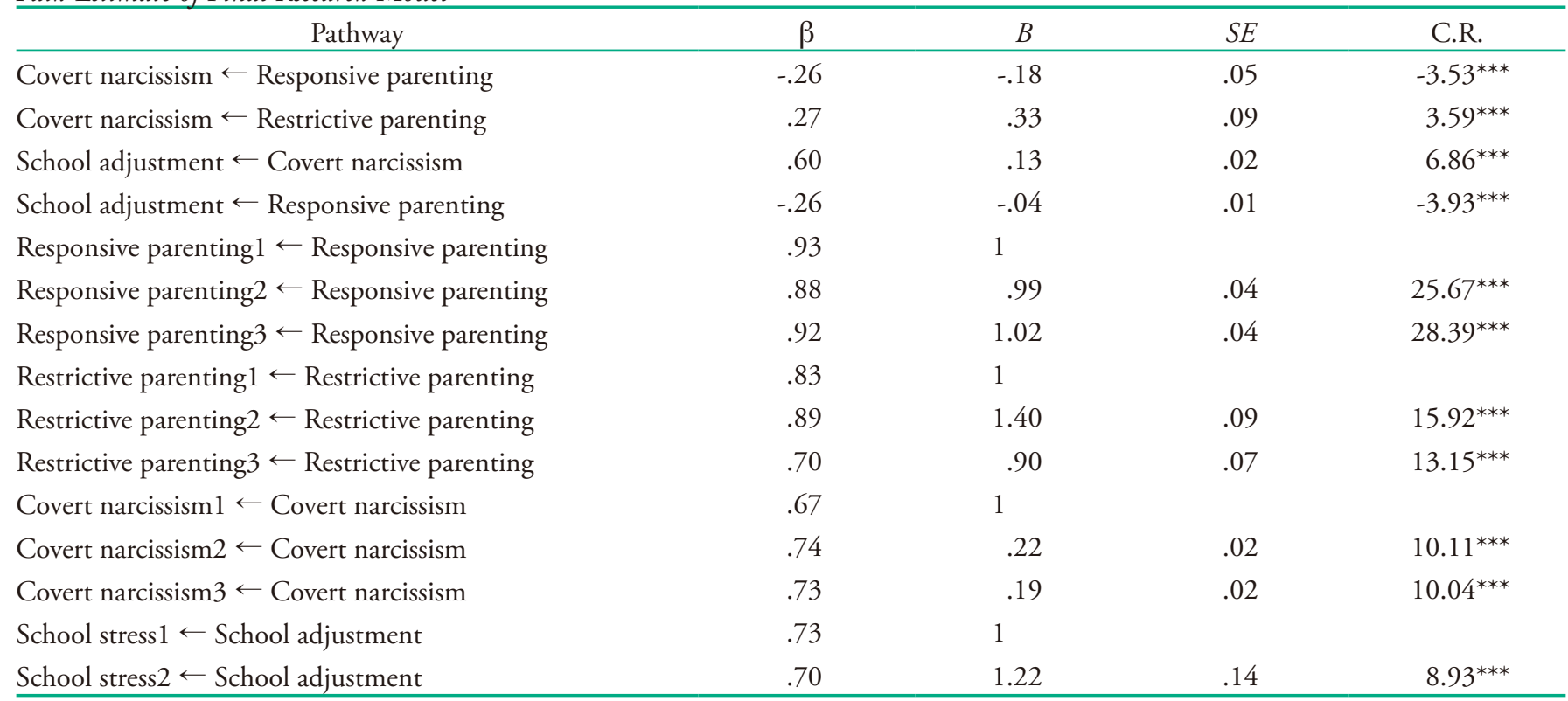

Note. $N=329$.

${ }^{* * *} p<.001$.

Table 4

Standardized Total Effect, Direct Effect and Indirect Effect in the Final Research Model

\begin{tabular}{|c|c|c|c|c|c|}
\hline Path & Total effect & Direct effect & Indirect effect & \multicolumn{2}{|c|}{$95 \%$ Confidence interval } \\
\hline Responsive parenting $\rightarrow$ School adjustment & $-.42^{* * *}$ & $-.26^{* * *}$ & $-.15^{* * *}$ & -.25 & -.06 \\
\hline Responsive parenting $\rightarrow$ Covert narcissism & $-.26^{* * *}$ & $-.26^{* * *}$ & - & & \\
\hline Restrictive parenting $\rightarrow$ Covert narcissism & $.27^{* *}$ & $.27^{* *}$ & - & & \\
\hline
\end{tabular}

Note. $N=329$.

${ }^{* *} p<.01 .{ }^{* * *} p<.001$.

bootstrapping 절차를 이용하여 경로모형의 전체효과를 직/ 간접효과로 분석하였다. 분석결과 Table 4에 나타나듯 간접경 로 계수의 $95 \%$ 신뢰구간 -.25 -.06에서 반응적 양육행동 $(\beta=$ $-.15, p<.001)$ 은 간접경로 계수의 $95 \%$ 신뢰구간 .06 .27에서 의 제한적 양육행동 $(\beta=.16, p<.01)$ 과 함께 내현적 자기애를 매개로 학교 적응에 간접영향을 미치는 것으로 나타났다. 학 교 적응에 대한 어머니의 반응적 양육행동, 제한적 양육행동, 내현적 자기애의 직접 효과의 상대적 크기를 살펴보면 어머 니의 반응적 양육행동 $(\beta=-.26, p<.001)$ 이 학교 적응을 유의 하게 설명한다고 하나, 초등학교 5,6 학년 아동의 학교 적응은 아동 자신의 내현적 자기애에 의해 상대적으로 가장 크게 설
명되는 것 $(\beta=.60, p<.001)$ 으로 나타났다. 이는 어머니의 양 육행동이 학령기 아동의 학교 적응에 유의한 영향을 미치지만 아동 자신의 개인 내적 특성이 더 영향력 있는 요인임을 시사 하는 것이다.

이러한 사실은 학령기 아동의 학교 적응 향상을 위해 아동 자신의 내현적 자기애가 발달되지 않도록 주의해야 함을 시사 하는 것이며 이를 위해 어머니들은 반응적 양육행동에 보다 많이 노력해야 함을 시사하는 것이다. 


\section{Discussion}

학령기 아동의 학교 적응을 어머니의 반응/제한적 양육행동 의 가정 환경 변인과 내현적 자기애의 개인 내적 변인 측면에 서 살펴보고자 한 이 연구는 초등학교 5, 6학년에 재학 중인 남녀 아동 329명을 대상으로 구조적 관계의 연구모형 분석을 실시하였다. 그리고 연구결과를 토대로 다음과 같은 결론을 도출하였다.

첫째, 학령기 아동의 학교 적응은 어머니의 반응/제한적 양 육행동에 의해 유의한 영향을 받는 것으로 나타났다. 학령기 아동이 지각한 어머니의 반응적 양육행동은 학교 생활 스트레 스로 평가된 학교 적응에 부적 영향을, 제한적 양육행동은 정 적 영향을 미치는 것으로 나타났다. 그러나 이러한 영향은 양 육행동의 질에 따라 다르게 나타났다. 어머니의 온정적이고 수용적일 뿐 아니라 아동의 자율성을 고려해 합리적 설명을 토대로 아동을 통제하려는 어머니의 반응적 양육행동은 학령 기 아동의 학교 생활 스트레스를 직접 낮추는데 영향을 미치 는 것으로 나타났다. 이에 반해 학령기 아동이 지각한 어머니 의 비난적이며 체벌 위주적인 제한적 양육행동은 아동의 학교 생활 스트레스에 직접 영향을 미치지 않지만, 내현적 자기애 성향을 높임으로써 학교 적응에 간접 영향을 미치는 것으로 나타났다. 이와 같은 연구결과는 어머니의 양육행동이 아동의 학교 적응에 영향을 미친다고 보고한 선행 연구(Chang et al., 2003; Chen et al., 2005; Dupere et al., 2015; Ladd, 2004; SturgeApple et al., 2008)의 결과와 유사하다고 볼 수 있다.

둘째, 학령기 아동의 내현적 자기애는 학교 적응에 유의한 영향을 미치는 것으로 나타났다. 아동 자신의 내현적 자기애 의 영향력은 어머니의 양육행동이 학교 적응에 영향을 미치는 것에 비해 상대적으로 높게 나타났다. 내현적 자기애의 경우 거만함과 과시성이 밖으로 표현되는 대신 타인의 반응에 과민 하고, 수줍어하며 자신에 대한 비판이나 비난에 쉽게 상처받 으며, 수치심이나 굴욕감에 매우 취약한 모습을 보인다(Akhtar \& Thomson, 1982). 이러한 내현적 자기애의 특성 때문에 내현 적 자기애적 성향이 높은 사람은 동료와의 대인관계에서 어려 움을 보고하는 경우가 높다(S.-Y. Kim \& Koh, 2016; Suh, Sin, $\& \mathrm{Kim}, 2011)$. 이러한 특성은 학령기 아동에게서도 나타나고 있다. 즉 내현적 자기애가 높은 아동은 또래 관계에서 어려움 을 경험하는 것으로 보고되고 있다(Chun, 2014; Pauletti et al., 2012). 한편 내현적 자기애적 성향의 사람은 주변 사람들이 자 신에게 부과한 기준과 기대를 충족시키려는 욕구가 강할 뿐 아니라 다른 사람에게 인정받으려는 욕구가 높기 때문에(Koo
$\& \mathrm{Kim}, 2014)$ 성적이나 시험불안과 같은 학업적 측면에서도 어려움을 경험하는 것으로 보고(Choi, 2005)되고 있다. 뿐만 아니라 거대자기환상을 갖고 있기 때문에 자신감이 부족하고 실패의 원인을 자신의 능력으로 귀인하기 때문에 학업에 대한 자기 효능감 역시 낮은 것으로 보고(H. S. Kim \& Kim, 2015)되 고 있다. 이러한 사실을 고려해 볼 때 내현적 자기애 성향이 높 은 학령기 아동은 학업 및 또래 관련 스트레스와 관련한 학교 적응에서 어려움을 경험하고 있음을 알 수 있다.

셋째, 학령기 아동이 지각한 어머니의 반응/제한적 양육행 동은 내현적 자기애를 매개로 학교 적응에 유의한 영향을 미 치는 것으로 나타났다. 학령기 아동이 지각한 어머니의 제한 적 양육행동은 내현적 자기애를 통제했을 때 학교 적응에 미 치는 직접 영향은 사라지고 내현적 자기애를 통한 간접 영향 만 나타났다. 이는 학령기 아동의 학교 적응이 어머니의 제한 적 양육행동에 의해 직접적으로 나타난다고 보기보다 어머니 의 제한적 양육행동에 의해 발달된 내현적 자기애에 의해 나 타날 수 있음을 시사하는 것이다. 어린 시절 부모로부터 냉정 하고 애정 결핍적인 양육행동이 방어적이고 나약하며 불안한 특성의 내현적 자기애를 발달시킨다는 선행 연구(Kernberg, 1975; E.-H. Kim, Chang, \& Cho, 2014; Kohut, 1977; Park \& Hong, 2014; Ramsey et al., 1996; Trumpeter et al., 2010)를 고려 해 볼 때, 어머니의 비난적이고 체벌 위주의 제한적 양육행동 은 자기 의심이 많으며 타인의 비난에 과도하게 반응하고 다 른 사람을 신뢰하지 못하거나 의지하지 못하는 내현적 특성 (Wink, 1991)을 강화시킨다고 볼 수 있다.

한편 학령기 아동이 지각한 어머니의 반응적 양육행동은 학교 적응에 직접 영향 외에 내현적 자기애를 통해 간접 영향 을 미치는 것으로 나타났다. 지지적이고 애정적인 양육행동은 내현적 자기애 성향을 낮춤으로써 내현적 자기애가 학교 적응 에 미칠 수 있는 영향력을 억제한다고 볼 수 있다. 흥미로운 것 은 내현적 자기애가 학교 적응에 미칠 수 있는 영향력 측면을 어머니의 양육행동과 연결시켜 고려해 보면 큰 차이는 아니지 만 반응적 양육행동보다 제한적 양육행동의 영향력이 상대적 으로 조금 더 크다는 것이다. 이러한 사실은 학령기 아동의 학 교 적응을 위협할 수 있는 내현적 자기애 성향을 발달시키지 않기 위해서는 어머니의 제한적 양육행동을 멈추는 것이 반 응적 양육행동을 높이는 것 이상으로 더 효과적임을 시사하는 것이다.

학교 생활에서 경험하는 스트레스를 중심으로 학교 적응을 접근한 이 연구는 “학교에 가기 싫다.”거나 “친구들과의 관계 에서 외롭다."는 등의 정서적 호소가 아동들의 학교 적응을 평 
가하는 중요 요소로 고려되어야 한다는 시각(Ladd, 2004; Ladd et al., 1997; Sturge-Apple et al., 2008)을 반영하고 있다. 학업이 나 친구 관계에서 경험하는 스트레스를 통해 학령기 아동의 학교 적응을 지각된 어머니의 반응적 양육행동과 제한적 양육 행동 그리고 아동 자신의 내현적 자기애적 성향 측면에서 살 펴본 이 연구의 결과는 초등학교 5, 6학년 자녀를 키우는 어머 니의 경우 반응적 양육행동을 높이고 제한적 양육행동을 낮춤 으로써 아동의 학교 적응을 지원해 줄 수 있음을 알려주고 있 다. 그러나 더 중요한 것은 어머니가 양육행동을 통해 학교 적 응에 직접적 영향을 미치려 하기보다 아동 스스로 학교 적응 을 높일 수 있도록 아동의 개인 내적 특성 안에 내현적 자기애 가 발달할 가능성을 미연에 예방하는 것이 보다 더 효과적임 을 알려 주고 있다.

학교 안에서의 집단 따돌림, 공격성 등 학교 폭력과 관련 하여 아동의 자기애적 성향에 대한 관심이 증가(Barry et al., 2003; Pauletti et al., 2012)하고 있지만 이에 관한 경험적 연구 가 상대적으로 취약한 국내 연구에서 학령기 아동의 스트레스 와 관련된 학교 적응을 내현적 자기애에 관련시켜 연구한 것 은 아동의 내현적 자기애에 대한 학문적 관심을 확장시킨다 는 측면에서 의미를 갖는다. 그럼에도 불구하고 이 연구는 학 교 적응에서 나타날 수 있는 내현적 자기애의 남녀 성차를 고 려하지 않았다. 이는 이 연구의 제한점이며 추후 연구의 제안 점이기도 하다. 자기애적 성인에게 나타나는 적응에서의 성차 (Morf \& Rhodewalt, 2001)처럼, 자기애적 남아는 자기애적 여 아와 다른 적응을 나타내고 있다. 자기애적 남아는 전통적 남 성 역할에 대한 고정 관념이 클수록 또래와의 관계에서 공격 적 성향을 나타난 데 비해 자기애적 여아는 전통적 성역할에 대한 고정 관념과 관계없이 또래 관계에서 공격성을 나타냈다 (Pauletti et al., 2012). 이러한 사실은 학령기 아동의 내현적 자 기애적 성향과 학교 적응 간 관계에서 성차가 나타날 수 있음 을 시사하는 것이다. 따라서 추후 연구에서 이를 고려한다면 학교 현장에서 내현적 자기애의 성차를 고려한 상담이나 지도 에 활용할 수 있을 것이다.

\section{Acknowledgements}

This study was supported by the sabbatical research grant from Daegu Catholic University in 2019

\section{Notes}

This article was presented at the 2019 Annual Spring Conference of the Korean Association of Child Studies.

\section{Conflict of Interest}

No potential conflict of interest relevant to this article was reported.

\section{References}

\section{In English}

Akhtar, S., \& Thomson, J. A. (1982). Overview: Narcissistic personality disorder. The American Journal of Psychiatry, 139(1), 12-20. doi:10.1176/ajp.139.1.12

Anderson, J. C., \& Gerbing, D. W. (1988). Structural equation modeling in practice: A review and recommended twostep approach. Psychological Bulletin, 103(3), 411-423. doi:10.1037/0033-2909.103.3.411

Atlas, G. D., \& Them, M. A. (2008). Narcissism and sensitivity to criticism: A preliminary investigation. Current Psychology, 27, 62-76. doi:10.1007/s12144-008-9023-0

Barry, C. T., Frick, P. J., \& Killian, A. L. (2003). The relation of narcissism and self-esteem to conduct problems in children: A preliminary investigation. Journal of Clinical Child and Adolescent Psychology, 32(1), 139-152. doi:10.1207/ S15374424JCCP3201_13

Becker, W. C. (1964). Consequences of different kinds of parental discipline. In M. L. Hoffman \& L. W. Hoffman (Eds.), Review of child development research (Vol. 1, pp. 169-208). New York: Russell Sage Foundation.

Chang, L., Schwartz, D., Dodge, K. A., \& McBride-Chang, C. (2003). Harsh parenting in relation to child emotion regulation and aggression. Journal of Family Psychology, 17(4), 598-606. doi:10.1037/0893-3200.17.4.598

Chen, X., Chang, L., He, Y., \& Liu, H. (2005). The peer group as a context: Moderating effects on relations between maternal parenting and social and school adjustment in Chinese children. Child Development, 76(2), 417-434. doi:10.1111/ j.1467-8624.2005.00854.x

Coolahan, K., McWayne, C., Fantuzzo, J., \& Grim, S. (2002). Validation of a multidimensional assessment of parenting styles for low-income African-American families with preschool children. Early Childhood Research Quarterly, 
17(3), 356-373. doi:10.1016/S0885-2006(02)00169-2

Dupere, V., Archambault, I., Leventhal, T., Dion, E., \& Anderson, S. (2015). School mobility and school-age children's social adjustment. Developmental Psychology, 51(2), 197-210. doi: $10.1037 / \mathrm{a} 0038480$

Erath, S. A., Flanagan, K. S., \& Bierman, K. L. (2008). Early adolescent school adjustment: Associations with friendship and peer victimization. Social Development, 17(4), 853-870. doi:10.1111/j.1467-9507.2008.00458.x

Foster, J. D., \& Trimm, R. F. (2008). On being eager and uninhibited: Narcissism and approach-avoidance motivation. Personality and Social Psychology Bulletin, 34(7), 1004-1017. doi:10.1177/0146167208316688

Harter, S. (1982). The perceived competence scale for children. Child Development, 53(1), 87-97. doi:10.2307/1129640

Hendin, H. M., \& Cheek, J. M. (1997). Assessing hypersensitive narcissism: A reexamination of Murray's narcism scale. Journal of Research in Personality, 31(4), 588-599. doi:10. 1006/jrpe.1997.2204

Horton, R. S., Bleau, G., \& Drwecki, B. (2006). Parenting narcissus: What are the links between parenting and narcissism? Journal of Personality, 74(2), 345-376. doi:10. 1111/j.1467-6494.2005.00378.x

Kernberg, O. (1975). Borderline conditions and pathological narcissism. Lanham, MD: Jason Aronson.

Kline, R. B. (2005). Principles and practice of structural equation modeling (2nd ed.). New York: The Guilford Press.

Kohut, H. (1977). The restoration of the self. New York: International Universities Press.

Ladd, G. W. (2004). Probing the adaptive significance of children's behavior and relationships in the school context: A child by environment perspective. Advances in Child Development and Behavior, 3, 43-104. doi:10.1016/s0065-2407 (03)31002-x

Ladd, G. W., Kochenderfer, B. J., \& Coleman, C. C. (1997). Classroom peer acceptance, friendship, and victimization: Distinct relational systems that contribute uniquely to children's school adjustment? Child Development, 68(6), 1181-1197. doi:10.1111/j.1467-8624.1997.tb01993.x

Lazarus, R. S., \& Folkman, S. (1984). Stress, appraisal, and coping. New York: Springer.

Malkin, M. L., Barry, C. T., \& Zeigler-Hill, V. (2011). Covert narcissism as a predictor of internalizing symptoms after performance feedback in adolescents. Personality and Individual Differences, 51(5), 623-628. doi:10.1016/j.paid. 2011.05 .031

Morf, C. C., \& Rhodewalt, F. (2001). Unraveling the paradoxes of narcissism: A dynamic self-regulatory processing model. Psychological Inquiry, 12(4), 177-196. doi:10.1207/ S15327965PLI1204_1
Pauletti, R. E., Menon, M., Menon, M., Tobin, D. D., \& Perry, D. G. (2012). Narcissism and adjustment in preadolescence. Child Development, 83(3), 831-837. doi:10.1111/j.14678624.2011.01731.x

Ramsey, A., Watson, P. J., Biderman, M. D., \& Reeves, A. L. (1996). Self-reported narcissism and perceived parental permissiveness and authoritarianism. Journal of Genetic Psychology, 157(2), 227-238. doi:10.1080/00221325.1996.9914860

Rose, P. (2002). The happy and unhappy faces of narcissism. Personality and Individual Differences, 33(3), 379-391. doi:10.1016/S0191-8869(01)00162-3

Russell, D. W., Kahn, J. H., Spoth, R., \& Altmaier, E. M. (1998). Analyzing data from experimental studies: A latent variable structural equation modeling approach. Journal of Counseling Psychology, 45(1), 18-29. doi:10.1037/00220167.45.1.18

Sturge-Apple, M. L., Davies, P. T., Winter, M. A., Cummings, E. M., \& Schermerhorn, A. (2008). Interparental conflict and children's school adjustment: The explanatory role of children's internal representations of interparental and parent-child relationships. Developmental Psychology, 44(6), 1678-1690. doi:10.1037/a0013857

Trumpeter, N. N., Watson, P. J., O’Leary, B. J., \& Weathington, B. L. (2008). Self-functioning and perceived parenting: Relations of parental empathy and love inconsistency with narcissism, depression, and self-esteem. The Journal of Genetic Psychology, 169(1), 51-71.

Wang, D., \& Fletcher, A. C. (2016). Parenting style and peer trust in relation to school adjustment in middle childhood. Journal of Child and Family Studies, 25(3), 988-998. doi:10.1007/ s10826-015-0264-x

Watson, P. J., Hickman, S. E., Morris, R. J., Milliron, J. T., \& Whiting, L. (1995). Narcissism, self-esteem, and parental nurturance. The Journal of Psychology, 129(1), 61-73. doi:10 $.1080 / 00223980.1995 .9914948$

Watson, P. J., Little, T., \& Biderman, M. D. (1992). Narcissism and parenting style. Psychoanalytic Psychology, 9(2), 231244. doi: $10.1037 /$ h0079344

Wink, P. (1991). Two faces of narcissism. Journal of Personality and Social Psychology, 61(4), 590-597. doi:10.1037/00223514.61.4.590

\section{In Korean}

Ahn, T. Y. (2016). The relationship between positive parenting behaviors, negative parenting behaviors, academic stress from extracurricular studies and learned helplessness in elementary school children. The Journal of Elementary Education, 29(4), 133-160.

Boo, K. (2009). Development and validation of the teacher rating 
scale of school adjustment for elementary school students. The Journal of Elementary Education, 22(4), 185-205.

Choi, I. H. (2005). A study on the relationships between narcissistic tendency and test anxiety of adolescents (Master's Thesis). Retrieved from http://www.riss.co.kr/link?id=T10019337

Chun, S. (2015). Mother's dysfunctional communication and children's aggression-The mediating effects of covert narcissism-. Korean Journal of Play Therapy, 18(1), 1-19. doi:10.17641/KAPT.18.1.1

Chung, N. W. (2001). A validational study of the Hypersensitivity Narcissism Scale (HSNS). The Korean Journal of Counseling and Psychotherapy, 13(1), 193-216.

Hong, S.-H., Gwak, P., \& Han, T. (2010). Construction and validation of narcissism scale for children. The Korea Journal of School Psychology, 7(3), 333-352. doi:10.16983/ kjsp.2010.7.3.333

Kang, J.-Y., \& Jin, M.-K. (2018). The effect of perceived parenting attitude on the interpersonal problems and the mediating effect of covert narcissism. Korean Journal of Family Welfare, 23(3), 489-509. doi:10.13049/kfwa.2018.23.3.5

Kim, E.-H., Chang, M.-S., \& Cho, H.-C. (2014). The mediational effect of vulnerability and covert narcissism in the relationship between adult attachment and social anxiety. Journal of Family and Counseling, 4(1), 35-57.

Kim, H. S., \& Kim, J. S. (2015). The mediating effect of academic self-efficacy and career decision making self-efficacy on the relationship between covert narcissism and employment anxiety of college students. Korean Journal of Youth Studies, 22(2), 223-244.

Kim, K. H. (2014). Effects of early adolescents' parent-child communication and parents' rearing attitudes on academic stress and cyber delinquency. Journal of Future Oriented Youth Society, 11(2), 1-22.

Kim, S.-Y., \& Koh, Y.-K. (2016). Influence of covert \& overt narcissistic personality on the interpersonal relationship stress in a work place. The Korean Journal of East West Science, 19(1), 19-34.

Koo, H.-K., \& Kim, J.-N. (2014). The relations between covert narcissism and psychological maladjustment: The mediating effect of internalized shame, maladaptive perfectionism, and perceived social support. Korea Journal of Counseling, 15(2), 609-636. doi:10.15703/kjc.15.2.201404.609

Lee, H.-J., \& Hong, S.-H. (2016). Children's covert narcissism, depression, social support and peer relationship problems. The Korean Journal of Elementary Counseling, 15(2), 121-
140.

Min, H. Y., \& Yoo, A. J. (1998). Development of a daily hassles scale for school age children. Korean Journal of Child Studies, 19(2), 77-96.

Park, W., \& Hong, S.-H. (2014). The mediating effects of rejection sensitivity on longitudinal causal relationships between negative parenting attitude and covert narcissism. The Korean Journal of School Psychology, 11(3), 455-477. doi:10. 16983/kjsp.2014.11.3.455

Shin, B. R., \& Lee, S. Y. (2018). The mediating effects of school adjustment on the relationship between adolescents' covert narcissism and depressive symptoms. Journal of Education \& Culture, 24(3), 331-350. doi:10.24159/joec.2018.24.3.331

Shin, H., Park, Y., Park, J., \& Lyu, J. (2006). Development and validation of the teacher rating scale of school adjustment behavior for elementary school students. The Korean Journal of School Psychology, 3(2), 1-26.

Son, C. S., Lee, J., \& Lee, M. S. (2015). The structural relationship among academic stress, learning motivation, and emotion regulation of elementary school students. Teacher Education Research, 54(1), 74-85. doi:10.15812/ter.54.1.201503.74

Suh, K.-H., Sin, H.-J., \& Kim, S.-S. (2011). Relationships between narcissism, self-esteem, interpersonal stresses, and social anxiety among children in early adolescence. Korean Journal of Youth Studies, 18(10), 143-160.

Yoo, S., Park, B., \& Doh, H.-S. (2015). Pathways from peer relationships to subjective well-being through self-esteem in late childhood. Korean Journal of Child Studies, 36(2), 5574. doi:10.5723/KJCS.2015.36.2.55

Yoo, Y., \& Park, I.-S. (2010). Comparisons of stress, self-esteem and perception of parents' nurturing attitudes in school-age children between Korea and China. Korean Parent Child Health Journal, 13(1), 26-34.

\section{ORCID}

Ha Young Min http://orcid.org/0000-0002-0376-2735

Received May 17, 2019

Revision received August 14, 2019

Accepted September 2, 2019 